\title{
GENERATION OF DIGITAL ELEVATION MODELS WITH HIGH-RESOLUTION OPTICAL SATELLITE IMAGES
}

\section{CARMEN VILLON, YAHAYDA LOAIZA, LUCERO RODAS, WILVER AUCCAHUASI}

Comisión Nacional de Investigación y Desarrollo Aeroespacial del Perú, Lima, Perú

\begin{abstract}
The SPOT family of satellites is made up of a constellation of Earth observation satellites. SPOT satellites have the ability to capture stereoscopic images of the same portion of land, whichallows the extraction of digital elevationmodels (DEM). This paperdescribes the process for extractingDEMsfrom SPOT-6 satellite images, whichincrease the ability to obtainresultswithhigherresolution at a scale of 1/10,000; the study area includes the province of Caylloma in the department of Arequipa. The digital model obtainedwillbeusedlater in the generation of interferograms to detect changes and/or deformation in the Macalandslide.

KEYWORDS: Interferogram, Photogrammetry, Lidar, Stereo pair, Epipolar geometry
\end{abstract}

Received: Jun 08, 2020; Accepted: Jun 28, 2020; Published: Sep 24, 2020; Paper Id.: IJMPERDJUN20201404

\section{INTRODUCTION}

A digital elevation model is a visual and mathematicalrepresentation of the height values with respect to the averagesealevel, whichallowscharacterizing the shapes of the relief and the elements or objectspresent in it. Such digital models (DEM) represent in a simplifiedway the variables measured by a three-dimensionalundulating surface (Forest 1997). Two of these dimensions refer to the orthogonal axes X and Y and the thirdmeasures the height $\mathrm{Z}$ of the thematic variable represented at each point in space (Bosque 1997). Digital elevationmodels are the basis for anygeographic information system, and are essential in geomorphological, hydrological, geological, vulnerability, and telecommunicationsstudies, amongothers.

There are variousways to obtain a DEM, either by applying point data interpolation, fromdigitisedlevelcurves, by extractingthemfromstereoscopic pairs of aerialphotographs or satellite images by photogrammetricprocedures, from radar images by interferometry or more recently by Lidar.

Digital photogrammetry uses image comparison techniques to estimate the elevation of objects in the fieldfromstereo pairs. Subsequently, the creation of DEMsfocuses on automaticprocessesthatmaximize the computationalresourcesavailabletoday.

Two satellites, the SPOT family, are launchedintoorbit, one in 1986 and the otherin 1990, withseveralearth stations receiving data. The main characteristicthatdistinguishesthemistheirlateral rotation capacity, whichincreases the temporal resolution, being able to observe any point of the terrestrial surface with a periodicity of between one and severaldays. This makesit possible to generatestereoscopic pairs of the observed zone, these data are contained in a file of type raster withregular structure, suchelevationmodels (DEM) are generatedusing computer equipment and specialized software. 


\section{METHODS Y MATERIALS STUDY ÁREA}

The presentstudywascarried out with SPOT-6 satellite images, whichmainlycover the Sabancayavolcano, and a part of the Colca Canyon where the Maca, Lari landslides are located, in the province of Caylloma in the department of Arequipa $\left(71^{\circ}\right.$ $52^{\prime} 12.09^{\prime \prime} \mathrm{W}, 15^{\circ} 44^{\prime} 20.33$ "S), is an Andeanmountainous area characterized by a range of heightsthat varies between $100 \mathrm{~m}$ and $3000 \mathrm{~m}$, itsorographyisquiteirregularwithslopesthatvarybetween $0^{\circ}$ and $84^{\circ}$ with the presence of water filtrations which are embedded at the foot of the slides, overloading the slope and favoring the slide. This zone ismainlycharacterized by the presence of areas of cultivationsuch as corn, quinoa, kiwicha, potatoes and others.

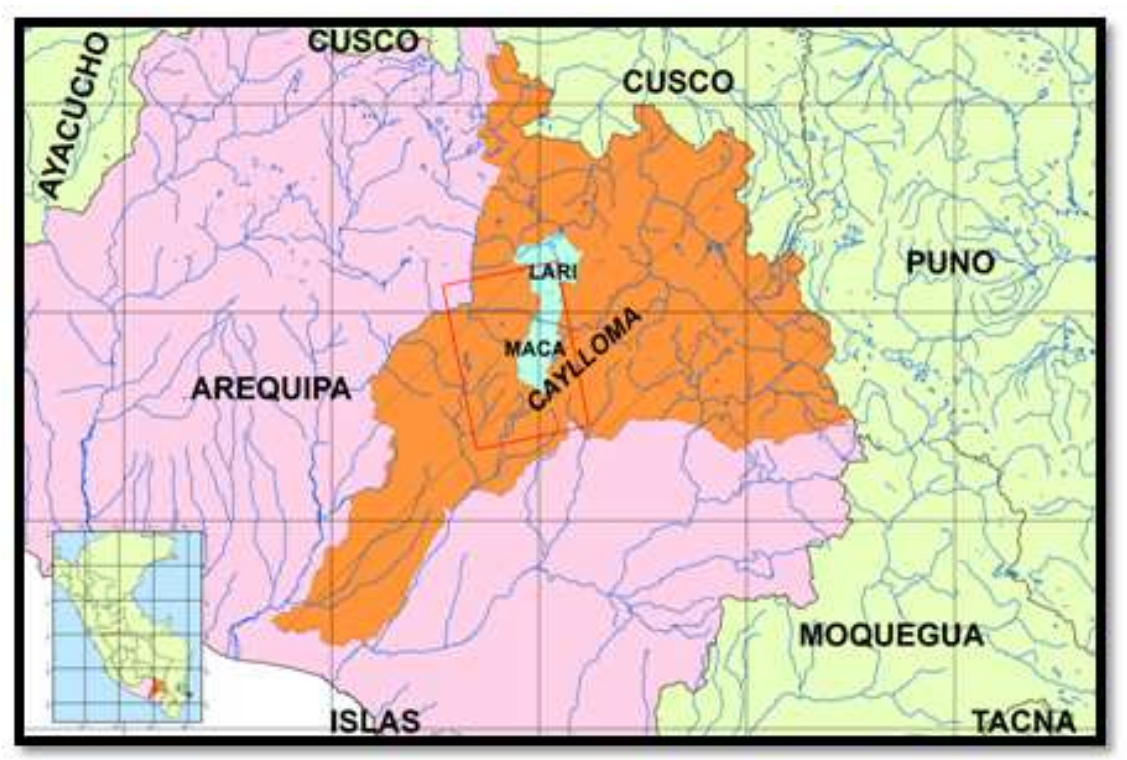

Figure 1 : Preliminary Evaluation of damages

\section{EXTRACTION OF DIGITAL ELEVATION MODELS}

In general, to extract the digital elevation model itisnecessary to perform the processessummarizedbelow

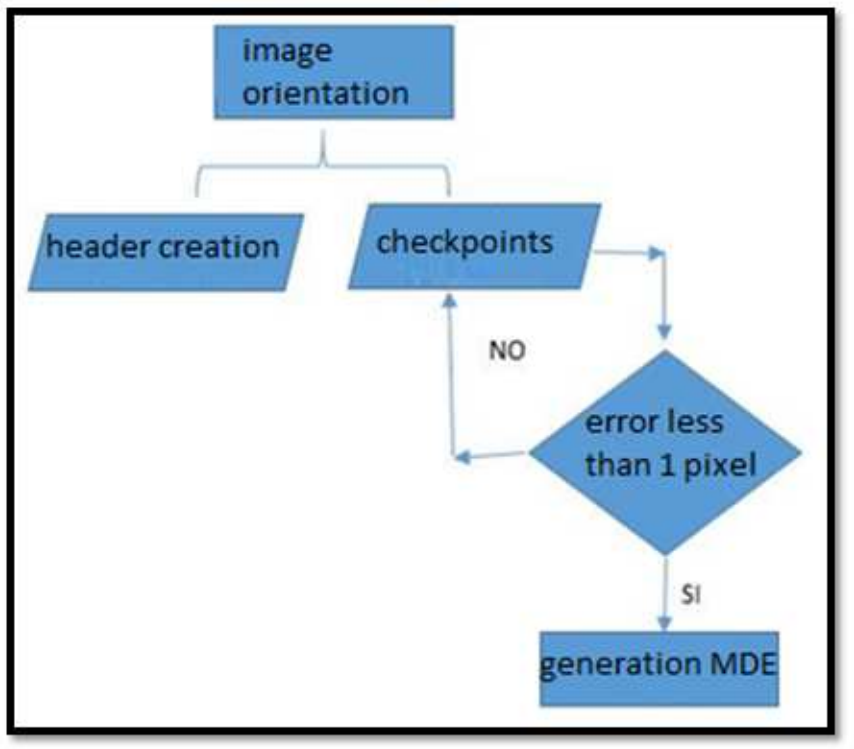

Figure 2 : Diagram of the extraction of digital elevation models 


\section{ACQUISITION OF STEREOSCOPIC IMAGES OF THE STUDY AREA}

The CMG gyroscopes allow the execution of quick maneuvers in all directions to observe several areas of interest in the samepass $\left(30^{\circ}\right.$ in $14 \mathrm{~s}$, including the stabilization time). Forward and backwardstereocapability - Stereo and tri-stereo in one pass.

The coverage of the SPOT-6 scene for thisworkis $30 \mathrm{Km}$ by $50 \mathrm{Km}$. These images capture information simultaneously in the 5 bands of the electromagneticspectrum, Panchromatic: 0,450-0,745 $\mu \mathrm{m}$ Blue: 0,450-0,520 $\mu \mathrm{m}$ Green:

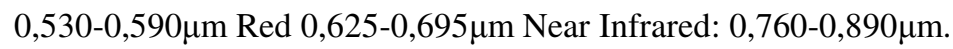

Pairs and trios of stereoscopic images captured in a single pass and in the sameorbit are used to generate DEM data. The SPOT-6 satellite canacquire pairs and trios of images over the areas of interestwith observation angles betweentwoconsecutive images that are only $15^{\circ}$ or $20^{\circ}$ apart, with a base/height ratio of between 0.27 and 0.4 .
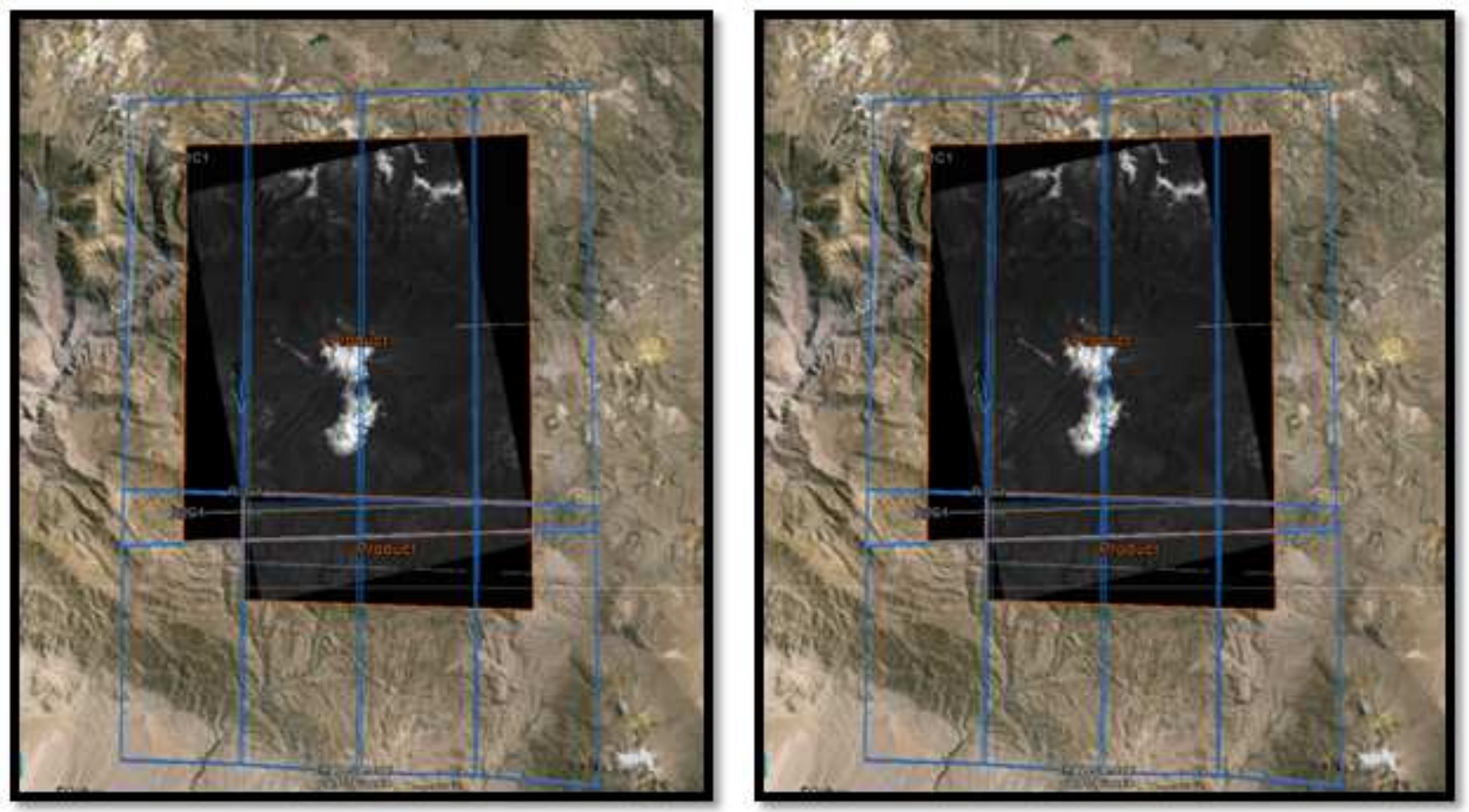

Figure 3 : SPOT 6 images shooting range

\section{NORMALIZATION OF THE SAME IN ORDER TO OBTAIN EPIPOLAR IMAGES}

Before the extraction of the DEM, itisnecessarythat the stereoscopic pair istransformedinto a pair of normalizedepipolar images which are parallel to the XY plane of the objectspace. Whentransforming the acquired images intoepipolarones, only the parallax in one direction isproduced and the corresponding points are aligned in the samerow or column. Therefore, the time required to perform the process of superimposing the images, whichwillthenallow the calculation of the magnitude of the parallax and based on it the elevation, isconsiderablyreduced. The normalization of the acquiredstereoscopic pair iscommonlydone by applyingepipolargeometrycriteria, the processcanbesummarized in the following points: (Morgan, 2004).

- It beginswith the location of a pixel in the normalized image (xn, yn).

- The corresponding location in the original image (xn, yn) iscalculatedusing the collinearityequations 
(equationsnumbers 1 and 2).

- The gray levels $\mathrm{g}(\mathrm{x}, \mathrm{y})$ in the original image are calculatedusing an appropriate interpolation methodsuch as nearneighbor, bilinear interpolation or cubic convolution.

- $\quad$ The interpolated gray value isassigned to the pixel of the normalized image $g(x n, y n)=g(x, y)$.

- $\quad$ The processisrepeated for all pixels in the normalized image.

- The processisgenerallyrepeated for the other image of the stereoscopic pair.

The relationshipsbetween the sensor, the image and the groundcanbedetermined on the basis of the collinearity condition whichspecifiesthat the position of the sensor, the point on the ground and itscorresponding point on the image must beplaced on a straight line, thatisthey must becollinear

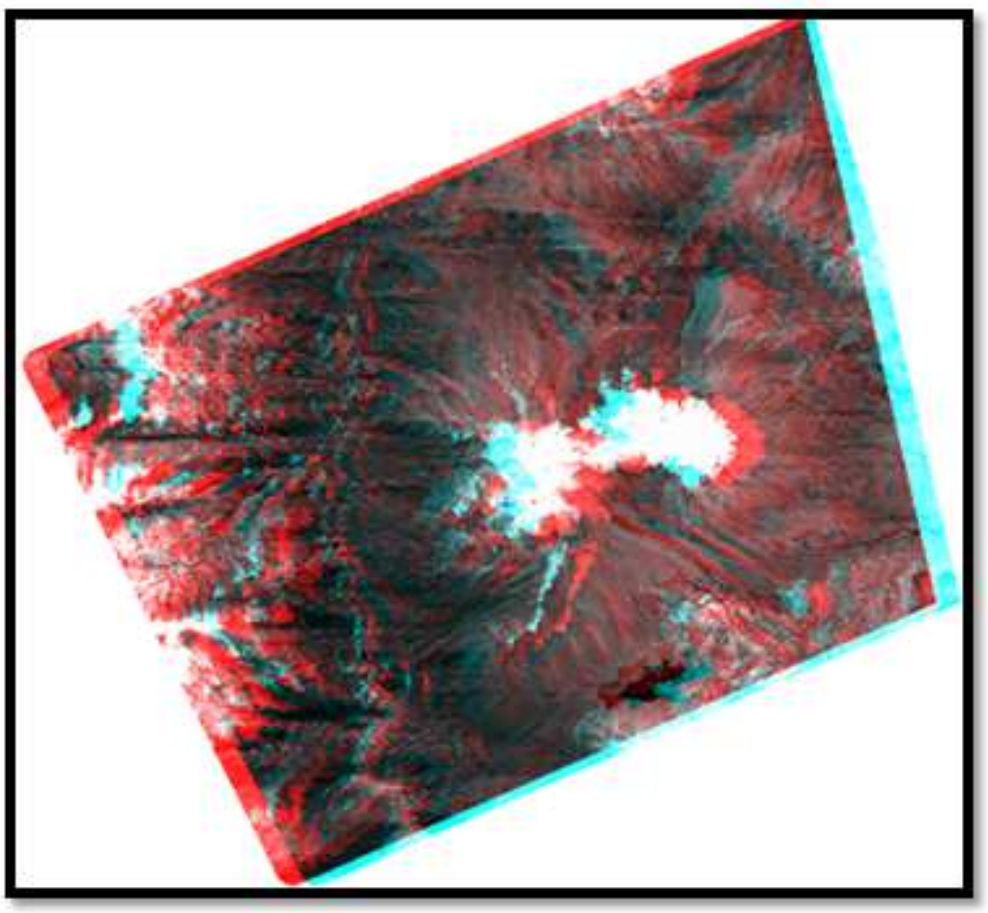

Figure 4 : Epipolar images takenfrom SPOT 6 stereo pair images

\section{GEOCODING THE EXTRACTED DEM USING GROUND CONTROL POINT}

In the presentworkweused a SPOT 6 image dated 02 and 28 January 2014 respectively, with a cloud coveragepercentage of $5 \%$ and the extraction processwascarried out applying PCI Geomatics 2014.To extract a georeferenced DEM, itisnecessary to have a series of control points (GCPs) withperfectlyknown position and elevation, fromwhichitis possible to assign real elevation values to each of the pixels of the extracted DEM.

Additionally, in places where no GCP isavailable, itisconvenient to collect points common to both images, which are locatedinteractively on the screen and whose position isknown, requiringonly an approximateelevation of them. The points contribute to increase the accuracy of the mathematical model used in the extraction of the DEM.

Control points werecollected in the fieldusingdifferential GPS. The points werecollected in easily identifiable places in the image and in the field, distributingthemthroughout the image and covering the altitudinal variation that the study area 
presents. Withthisprocedure, approximately 28 points werecollected in the field.
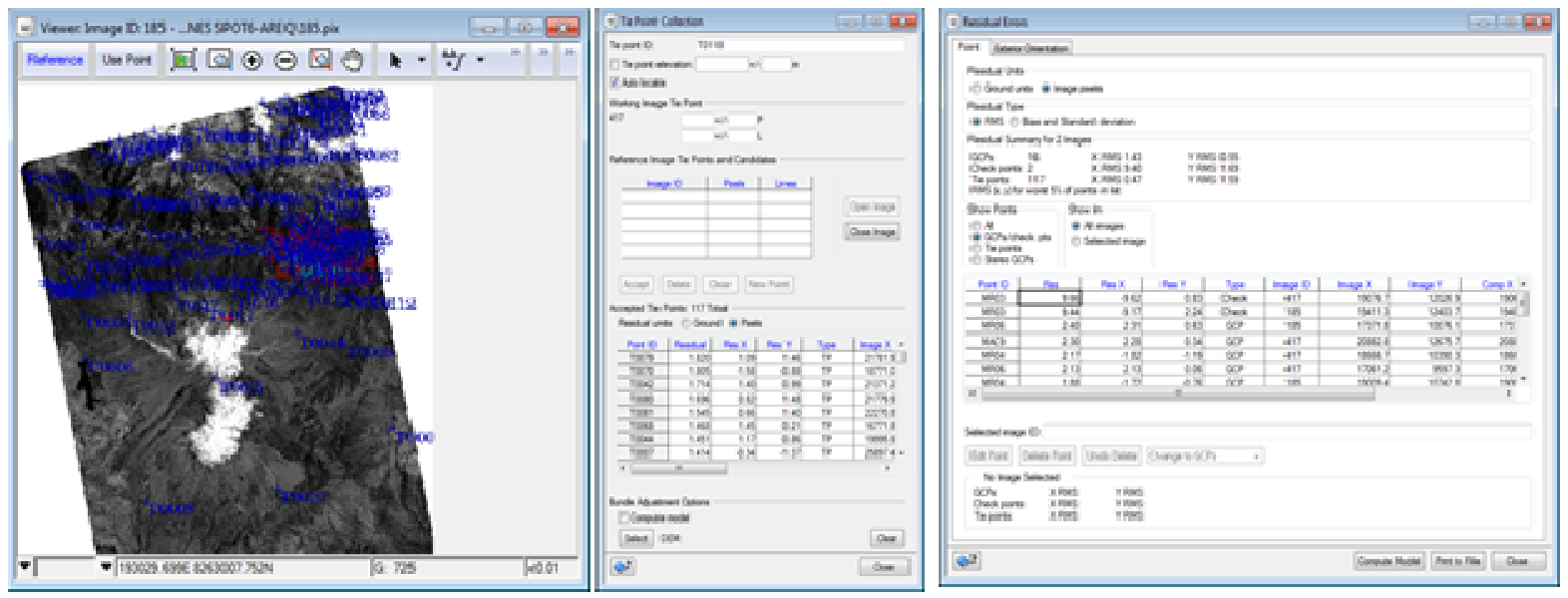

Figure 5 : Location of control points and tie points, for the correction of the stereo pair SPOT-6.

The accuracy of the procedure to generate DEM from SPOT images is high given the factthat the collinearityequations on which the algorithms are basedallow to obtain a direct relationshipbetween the image coordinates and the targetcoordinates. In thisway, relative orientation and model coordinates are obtained, and calibration parameterscanbeincluded in the systematicerroradjustment.

\section{RESULTS}

In the digital elevation model of the district of Macaobtained, itcanbeseenthat in the lower part of the image, thereis no consistency in the relief of the terrain (see Fig. A), due to the factthatthere are no reference points in that area, compared to the upper part of the image where the relief of the terrain is more consistent (see Fig. B), and itispreciselywheremost of the control points wereplaced.

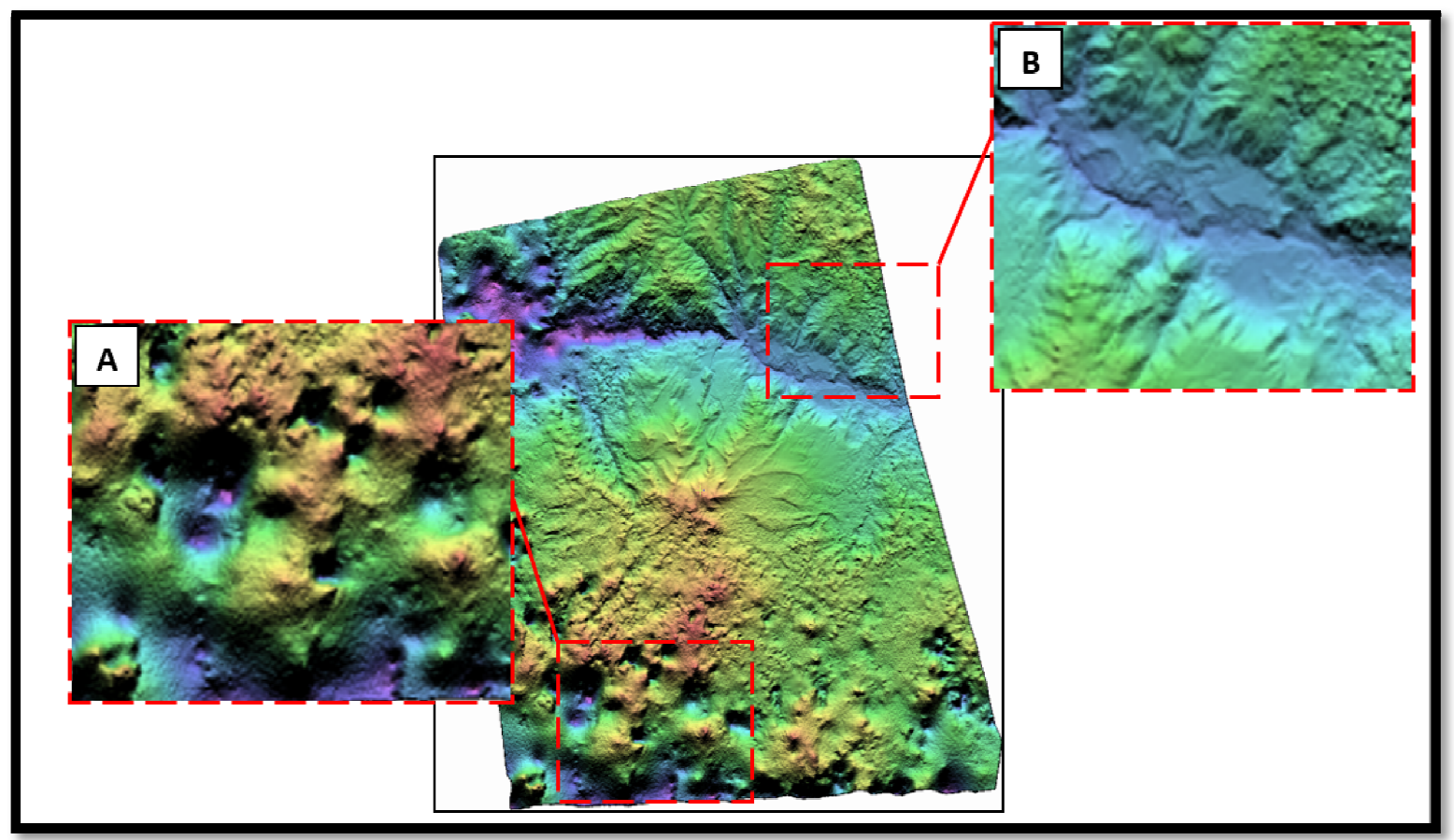

Figure 6 : Digital elevation model (DEM) of $5 \mathrm{~m}$ spatial resolution obtained from the processwithGeomática PCI 2014 software. 


\section{CONCLUSIONS}

- One way to improve the quality of stereoscopic data is to reduce the time between the two shots, i.e. by capturing the data simultaneously.

- The capture of control points must be carried out independently of any other previous mapping source and with a high degree of accuracy.

- The extraction of a DEM with good accuracy is subject to the accuracy of the control points used to georeferenceit.

- The quality of the DEM depends largely on the quality and location of the GCPs

- It is important to take into account the values of the GCP and Tie Point obtained at the time of calculating the errors to obtain a DEM with the adequate quality for the generation of the products derived from it.

- Obtaining digital elevation models as a source of data can beused for orthorectification of satellite images, generation of cartography and data modeling.

\section{REFERENCES}

1. Bosque, J., 1997, Sistemasde InformaciónGeográfica, Madrid, Riapl.

2. Morgan, M., 2004, EpipolarResampling of LinearArray Scanners Scenes, Ph.DThesis, University of Calgary.

3. Campbell J., 2011, Introduction to Remote Sensing, New York

4. Taylor \& Francis Group, 2008, Advances in Photogrammetry, Remote Sensing and Spatial Information Sciencies: 2008 ISPRS CongressBook, Florida.

5. Wegmüller, U., Santoro, M., Werner, Ch., Strozzi, T., 2009 , DEM Generation Using ERS-ENVISAT Interferometry, Gümligen, Switzerland

6. Gelautz, M., Paillou, P., Chen, C. W., Zebker, H. A., A Comparative Study Of Radar Stereo And Interferometry For Dem Generation, Frascati, Italy. 